\title{
Low perceived control as a risk factor for episodic memory: the mediational role of anxiety and task interference
}

\author{
Margie E. Lachman • Stefan Agrigoroaei
}

Published online: 15 September 2011

(C) Psychonomic Society, Inc. 2011

\begin{abstract}
Low perceived control is considered a risk factor for poor cognitive functioning, but the mechanisms are unclear. The goal of the present study was to analyze anxiety and task interference as sequential mediators of the association between control beliefs and episodic memory. Cognitive-specific control beliefs were assessed prior to the lab session. State anxiety was assessed in the lab, followed by a word list recall task. The frequency of intrusive thoughts during the memory task was reported by the participants as a measure of task interference after the completion of the cognitive testing. The results for 152 participants from the ages of 22 to 84 years supported the predicted three-path mediation model. Lower levels of control beliefs were associated with higher state anxiety, which in turn affected episodic memory performance by increasing the likelihood of task interference, with age, sex, and verbal abilities as covariates. The implications of the results for developing interventions to improve memory performance are considered.
\end{abstract}

Keywords Memory· Interference/inhibition in memory retrieval $\cdot$ Perceived control $\cdot$ Anxiety

Although aging is commonly associated with memory problems, there is robust evidence for individual differences in memory performance in middle and later adulthood

\footnotetext{
M. E. Lachman $\cdot$ S. Agrigoroaei

Brandeis University,

Waltham, MA, USA

M. E. Lachman ( $\square)$

Department of Psychology, MS 062, Brandeis University,

Waltham, MA 02454, USA

e-mail: Lachman@brandeis.edu
}

(Hertzog, Kramer, Wilson, \& Lindenberger, 2008; Salthouse, 2009). Recently, studies have focused on identifying modifiable factors that can account for these individual differences, with a goal of designing preventative and remedial interventions. One such promising factor, personal control beliefs, has been found to play a central role in maintaining and optimizing cognitive health in adulthood and old age (Hertzog et al., 2008; Krause, 2007; Lachman, Andreoletti, \& Pearman, 2006; Rowe \& Kahn, 1998; Windsor \& Anstey, 2008). Those who believe that they can engage in behaviors in order to maintain or improve their cognitive functioning, even in the face of losses and declines, show higher levels of memory performance (Lachman, Neupert, \& Agrigoroaei, 2011). Nevertheless, only a small number of studies have focused on identifying the mechanisms relating control beliefs to memory. Understanding the processes whereby beliefs about control have an impact on memory performance can provide valuable information for identifying sources of memory problems and developing strategies and treatments to improve memory at all ages.

In the present study, we focused on whether anxiety associated with the evaluative testing situation and internal cognitive task interference (mind wandering) operate as sequential mediators linking control beliefs to memory performance. We present and integrate the existing findings and theoretical models regarding the direct and indirect associations between control beliefs, anxiety, task interference, and memory performance.

\section{Control beliefs and memory performance}

Several cross-sectional studies have shown that higher perceived control is tied to better memory, especially 
among older adults (e.g., Hertzog, McGuire, \& Lineweaver, 1998; Seeman, McAvay, Merrill, Albert, \& Rodin, 1996; Valentijn et al., 2006). Longitudinal research has shown a similar pattern in that low control beliefs were related to greater declines in cognitive functioning over 20 years (Caplan \& Schooler, 2003), and increases in control beliefs were associated with better episodic memory performance (Windsor \& Anstey, 2008).

\section{Mechanisms linking control beliefs and memory performance}

Control beliefs may have behavioral, motivational, cognitive, affective, and physiological consequences, which in turn have an impact on a large spectrum of age-related outcomes, such as cognitive performance and physical health (Lachman et al., 2011; Miller \& Lachman, 1999). A sense of control is a fundamental core set of self-regulatory beliefs that affects how situations are perceived and provides motivation for whether or not to exert effort or attempt new tasks (Bandura, 1997). Control beliefs are associated with engagement in different behaviors that are beneficial for memory functioning. Individuals with higher control beliefs are more likely to engage in cognitive activities, a protective factor for memory performance (Jopp \& Hertzog, 2007; Lachman, Agrigoroaei, Murphy, \& Tun, 2010). Along the same lines, personal beliefs about control and self-efficacy are related to the frequency of computer use (Czaja et al., 2006), another protective factor for cognition (Tun \& Lachman, 2010).

Several studies have revealed that higher control beliefs are related to effective compensatory strategy use (Hertzog et al., 1998; Lachman \& Andreoletti, 2006; Lachman et al., 2006) and effective goal setting (West \& Yassuda, 2004), which in turn are associated with better memory performance. The relationship between control beliefs and recall was mediated by strategy use for the middle aged and was partially mediated for older adults (Lachman \& Andreoletti, 2006). Amrhein, Bond, and Hamilton (1999) also found that older adults with a lower sense of control had lower episodic memory recall and used less categorical clustering, whereas the younger adults did not show any effects of control beliefs on either clustering or recall performance. In addition, Riggs, Lachman, and Wingfield (1997) showed that during cognitive tests, those with higher control beliefs estimated and monitored their capacities better than those with lower control beliefs.

The role played by the level of affective arousal in relation to control beliefs and memory remains virtually unexplored. Different overlapping concepts are used to designate the affective processes that accompany the evaluative testing situation: state anxiety, test anxiety, evaluative anxiety, stress reactivity, or situational stress.
State anxiety-namely, the currently experienced level of anxiety - is theoretically determined by both trait anxiety and situational stress (Dobson, 2000; Eysenck \& Calvo, 1992). Moreover, the processes underlying the role played by stress and anxiety in cognitive functioning usually overlap. For instance, concepts such as worry and rumination were studied as common responses to both stressful events and test anxiety (Brosschot, Gerin, \& Thayer, 2006). Because stress and anxiety are similar constructs and are often operationalized in the same way, we use these terms interchangeably in the present study.

Stress and anxiety were identified in previous work (e.g., Beaudreau \& O'Hara, 2009; Endler, Speer, Johnson, \& Flett, 2001; Lupien et al., 2005; Lupien et al., 1997; Neupert, Stawski, \& Almeida, 2008; Stawski, Sliwinski, \& Smyth, 2006, 2009; Wetherell, Reynolds, Gatz, \& Pedersen, 2002) as factors related to individual differences in cognition, with higher levels of stress and anxiety associated with poorer cognitive performance. Depression and anxiety had a stronger impact than physical health on long-term cognitive functioning over a 6-year period in the Maastricht Aging Study (van Hooren et al., 2005). Also, anxiety appears to be more detrimental for older than for younger adults in terms of memory (Andreoletti, Veratti, \& Lachman, 2006), divided attention (Hogan, 2003), and cognitive decline (Sinoff \& Werner, 2003).

Anxiety and stress are also related to control beliefs. Perceived uncontrollability over challenge, as well as other related concepts such as learned helplessness (Peterson, Maier, \& Seligman, 1993), are well documented as being associated with higher physiological and self-report indicators of stress and anxiety. For example, lower perceived control was shown to be associated with higher state anxiety (Endler et al., 2001). Other results revealed that an acute stressor negatively affects the immune system, especially if it is perceived as uncontrollable (Brosschot et al., 1998; Kemeny, 2003). On the other hand, experiencing personal control in a challenging situation has been shown to reduce stress-related neuroendocrine responses such as in the hypothalamicpituitary-adrenal (HPA) axis response (Kemeny, 2003; Kirschbaum et al., 1995; Seeman \& Robbins, 1994).

\section{Anxiety, task interference, and memory performance}

There are multiple theoretical models about the processes linking anxiety and memory. The central idea shared by the different models is that anxious individuals are more likely to allocate cognitive resources to negative thoughts (e.g., worry) and are more prone to intrusive thinking, which interferes and competes with resources in working memory.

In other words, the failure to inhibit distracting thoughts, which is characteristic of anxious individuals, is detrimental 
to maintaining attentional focus needed for successful cognitive performance. According to the cognitive interference theory (Sarason, 1988), the intrusive thoughts characteristic of participants with higher levels of anxiety reduce the attentional resources that can be allocated to the ongoing task and therefore are deleterious to performance.

The role of anxiety and intrusive thoughts is also invoked by the processing efficiency theory (Eysenck \& Calvo, 1992). This theory makes the distinction between performance effectiveness (level of performance) and processing efficiency (the amount of effort necessary to reach a certain level of performance) and suggests that intrusive thoughts reduce both processing and performance. More precisely, intrusive thoughts require the mobilization of additional resources (e.g., on-task effort) to overcome the deleterious effects of distraction on performance. The processing efficiency theory suggests that anxiety should have an effect on working memory and other aspects of memory demanding sustained attentional resources.

A more comprehensive theoretical account regarding the association between anxiety and performance is the attentional control theory (Derakshan \& Eysenck, 2009; Eysenck, Derakshan, Santos, \& Calvo, 2007). The theory assumes that anxiety increases the level of distractibility. In other words, higher levels of anxiety have an impact on the inhibition functions responsible for the suppression of irrelevant information and reduce the attentional focus on the ongoing task.

Several studies have revealed a positive relationship between test anxiety and cognitive interference (the degree to which intrusive thoughts interfere with task-relevant performance, Ferraro \& Washington, 2005; Hammermaster, 1989; Kurosowa \& Harackiewicz, 1995; Mayer \& Hanges, 2003). With respect to the directionality of this association, there is experimental evidence showing that high levels of evaluative anxiety can cause cognitive interference (Coy, O'Brien, Tabaczynski, Northern, \& Carels, 2011). Using an anxiety induction procedure, Coy and colleagues showed that the participants assigned to the high anxiety condition reported more negative off-task self-dialogue.

Task interference has been identified in several studies as a process directly related to high levels of anxiety and stress (e.g., Stawski et al., 2006) and negative life experiences (Yee, Edmondson, Santoro, Begg, \& Hunter, 1996). Moreover, higher levels of interference are associated with poorer performance, as measured by working memory, speed of processing, and episodic memory tasks (Klein \& Boals, 2001; Stawski et al., 2006). Several studies have shown that mind wandering is detrimental in terms of signal detection, encoding, and comprehension (Smallwood, McSpadden, \& Schooler, 2008). Task interference has also been shown to mediate the relationship between anxiety and different cognitive functions (Coy et al., 2011;
Kurosowa \& Harackiewicz, 1995). For example, Coy and colleagues showed that evaluation anxiety led to increased rumination (negative off-task self-dialogue), which then resulted in diminished working memory (phonological loop) performance. This pattern of results is consistent with the theoretical models that suggest that low resistance to task interference is a proximal determinant of cognitive performance and an explanatory mechanism of cognitive aging.

The inhibitory deficit theory (Hasher \& Zacks, 1988) postulates that greater levels of difficulty in inhibiting taskirrelevant information underlie the broad spectrum of cognitive deficits in normal aging. Along the same lines, the framework developed by Clapp and Gazzaley (2010) suggests that internal interference, caused by intrusions (mind wandering) or diversions (multitasking), as well as external interference, caused by distractions (irrelevant stimuli) or interruptions (multitasking), account in part for age differences in cognitive performance. Consistent evidence was found by Stawski et al. (2006), showing that older adults are more likely than the younger participants to experience task interference when performing cognitive tasks. Also, the impact of interference on cognitive performance seems to be greater for older adults than for younger adults (May, Hasher, \& Kane, 1999).

The integration of this theoretical and empirical evidence leads to a natural next step toward understanding the possible pathways whereby control beliefs and memory performance are related. The specific goal of the present study was to examine whether this relationship is mediated by state anxiety and task interference. On the basis of past work, we predicted a three-path mediational model: Those with lower control beliefs would experience higher levels of state anxiety, and anxiety would impair memory performance by increasing the likelihood of intrusive thoughts. We also examined whether the hypothesized relationships would show variations by age.

\section{Method}

\section{Participants}

Participants were 152 adults recruited from a list of names randomly sampled by Survey Sampling International from all of the zip codes located within a 10-mile radius of the test site located in a city in west suburban Boston. The sample was obtained after applying several exclusion criteria including poor self-rated health (as compared with other people the same age), low level of educational attainment (no high school degree or General Education Diploma), and a history of stroke in the last 5 years, serious head injury, Parkinson's disease, or other neurological 
disorders. Also, non-native English speakers (or those who learned English after age 10) and those with more than two errors on the Pfeiffer Short Portable Mental Status Questionnaire (Pfeiffer, 1975) were excluded. The respondents with complete data $(N=149)$ ranged in age from 22 to 84 years $(M=57.25, S D=15.57)$ and included $45.6 \%$ women. The level of education ranged from 12 to 20 years $(M=16.95, S D=2.14)$, with $82.5 \%$ having a Bachelor's degree or higher.

\section{Measures}

Control beliefs The participants completed the Personality in Intellectual Aging Contexts inventory (Lachman, Baltes, Nesselroade, \& Willis, 1982), an instrument that captures the level of perceived control over cognitive performance. As in previous work (Lachman \& Andreoletti, 2006), the final score was computed with three 12 -item subscales: internal (e.g., "I know if I keep using my memory I will never lose it"), chance (e.g., "There's nothing I can do to preserve my mental clarity"), and powerful others (e.g., "I can only understand instructions after someone explains them to me"). Participants indicated the degree to which they agreed with each statement, using a scale ranging from 1 (strongly agree) to 6 (strongly disagree). First, the items of the internal subscale were recoded. Then, all 36 items were averaged (Cronbach's Alpha $=.83$ ) to create the final score, which ranged from 3.50 to 6 . Higher values were associated with higher perceived control over cognitive functioning.

State anxiety An abbreviated version of the Spielberger StateTrait Anxiety Inventory (Spielberger, Gorsuch, \& Luskene, 1970) was administered. It consisted of the 10 odd items from the scale. The participants had to indicate how closely different statements (e.g., "I am tense, I am worried") matched their current feelings - at that moment - on a 4point scale ranging from 1 (not at all) to 4 (very much so). The mean of the 10 items (Cronbach's Alpha $=.85$ ) ranged from 1 to 3.10 and was used as an indicator of state anxiety. Higher values reflected higher levels of anxiety.

Task interference We used the Cognitive Interference Questionnaire (Sarason, Sarason, Keefe, Hayes, \& Shearin, 1986) to measure the frequency of extraneous thoughts experienced by the participants while working on the memory tasks $(1=$ never, $5=$ very often $)$. We included the 21 statements referring to the frequency of task-relevant worries (e.g., "I thought about how poorly I was doing") and task-irrelevant thoughts (e.g., "I thought about something that happened earlier today"). The mean of the 21 items (Cronbach's Alpha $=.86$ ) was computed. The final score of task interference ranged from 1.14 to 3.86 .
Episodic memory Episodic memory performance was assessed using a categorizable word list free recall task (Hertzog, Dixon, \& Hultsch, 1990). The participants had to recall a list of 30 words that fit into five taxonomic categories (i.e., flowers, metals, trees, sports, and animals). The words were randomly ordered so that those from the same category were not presented adjacent to one another. The task involved three trials: two immediate and one delayed. First, the participants were asked to study the list for $3 \mathrm{~min}$ and had as much time as needed to write down as many words as possible, without any cues. Second, immediately following this task, participants had a 1-min study period of the same words, and as much time as they needed to recall them. Third, after a delay of approximately 25 minutes, during which respondents carried out other tasks, they were asked again to recall as many words as they could, without an additional study period. Each participant received three individual scores representing the number of items correctly recalled during the immediate and delayed trials. The measure of episodic memory was obtained by averaging the three scores, with a range from 6.67 to 30 .

Verbal abilities Verbal abilities were assessed using part one of the Extended Range Vocabulary Test from the Educational Testing Service Kit of Factor Referenced Cognitive Tests (Ekstrom, French, Harman, \& Derman, 1976). Participants had to answer 24 multiple-choice vocabulary questions. Each question consisted of a vocabulary word followed by five answer choices, and the participant had to select the word that was most nearly a synonym to the original word. The participant received a score of 1 for each correct answer, a score of 0 for each question left blank, and a score of -.25 for each incorrect answer. The computed sum of the individual scores ranged from .25 to 24 and was used as an indicator of verbal abilities.

Self-rated health Participants rated their level of overall health on a scale from 0 (the worst possible health) and 10 (the best possible health), with scores ranging from 3 to 10 .

Depression We used the short form of the Geriatric Depression Scale (Sheikh \& Yesavage, 1986). The scale contains 15 yes $(=1) / \mathrm{no}(=0)$ questions (e.g., "Are you basically satisfied with your life?" and "Do you often feel helpless?"). Several items were recoded so that a higher score represented a greater likelihood of depression. The final sum score ranged from 0 to 14 .

Procedure

Participants were informed that the study focused on problem solving and memory performance and involved 
Table 1 Descriptive statistics and bivariate correlations among study variables

\begin{tabular}{|c|c|c|c|c|c|c|c|c|c|c|c|}
\hline Variable & $M$ & $S D$ & Age & Sex & Education & $\begin{array}{l}\text { Self-Rated } \\
\text { Health }\end{array}$ & Depression & $\begin{array}{l}\text { Verbal } \\
\text { Abilities }\end{array}$ & $\begin{array}{l}\text { Control } \\
\text { Beliefs }\end{array}$ & $\begin{array}{l}\text { State } \\
\text { Anxiety }\end{array}$ & $\begin{array}{l}\text { Task } \\
\text { Interference }\end{array}$ \\
\hline Age (years) & 57.25 & 15.57 & & & & & & & & & \\
\hline $\operatorname{Sex}(-1=$ men, $1=$ women $)$ & - & - & -.11 & & & & & & & & \\
\hline Education (years) & 16.95 & 2.14 & -.13 & -.02 & & & & & & & \\
\hline Self-rated health & 8.14 & 1.28 & .03 & .003 & .09 & & & & & & \\
\hline Depression & 1.60 & 2.24 & $-.27 * *$ & .01 & $-.17 *$ & $-.40 * * *$ & & & & & \\
\hline Verbal abilities & 14.60 & 4.75 & $.24 * *$ & -.01 & $.38 * * *$ & .02 & -.15 & & & & \\
\hline Control beliefs & 5.11 & .48 & .05 & -.05 & .16 & .06 & $-.29 * * *$ & $.17 *$ & & & \\
\hline State anxiety & 1.54 & .45 & -.10 & $.25^{* *}$ & -.13 & -.13 & $.39 * * *$ & -.13 & $-.35 * * *$ & & \\
\hline Task interference & 1.94 & .45 & $-.32 * * *$ & .09 & -.11 & -.06 & $.26^{* *}$ & -.11 & $-.30 * * *$ & $.35 * * *$ & \\
\hline Word list recall & 21.83 & 4.67 & $-.34 * * *$ & $.22 * *$ & $.17 *$ & .05 & -.09 & $.20^{*}$ & $.24 * *$ & $-.18 *$ & -.13 \\
\hline
\end{tabular}

${ }^{*} p<.05, * * p<.01, * * * p<.001, N=149$

filling out mailed questionnaires, as well as an in-person lab testing session. The control beliefs questionnaire was filled out at home before coming to the lab. At the beginning of the lab session, participants completed a state anxiety measure. Next, they participated in a driving simulation experiment for about $25 \mathrm{~min}$, which was unrelated to the present study. After the driving study, they completed all trials of the episodic memory task. The level of task interference was assessed retrospectively, after the memory testing was completed.

\section{Data analysis}

The data analysis includes participants with complete data on all variables of interest $(N=149)$. The means, standard deviations, and intercorrelations were computed for all variables and are presented in Table 1.

The three-path mediation model (Fig. 1) was tested using the joint significance test approach (Taylor, MacKinnon, \& Tein, 2008). According to simulation results (MacKinnon, Lockwood, Hoffman, West, \& Sheets, 2002), this approach provides the best balance between a small Type I error and high statistical power. This approach tests each path of the meditational chain, and it entails the use of three individual regression models, one for each of the outcomes (mediator 1 [state anxiety], mediator 2 [task interference], and dependent variable [episodic memory]):

(Model 1) State Anxiety $=\beta_{01}+\beta_{1}$ Control Beliefs $+\varepsilon_{1}$. (Model 2) Task Interference $=\beta_{02}+\beta_{2}$ Control Beliefs $+\beta_{3}$ State Anxiety $+\varepsilon_{2}$.

(Model 3) Episodic Memory $=\beta_{03}+\beta_{4}$ Control Beliefs $+\beta_{5}$ State Anxiety $+\beta_{6}$ Task Interference $+\varepsilon_{3}$.

In the context of our study, the first estimated model included the association between control beliefs and state anxiety. Second, task interference was regressed on both control beliefs and state anxiety. In the third model, control beliefs, state anxiety, and task interference were all included as predictors of memory performance. According to the joint significance test, the evidence for the mediation is found if the following three paths are jointly significant: the association between control beliefs and state anxiety $\left(\beta_{1}\right)$, between state anxiety and task interference $\left(\beta_{3}\right)$, and between task interference and memory performance $\left(\beta_{6}\right)$ ]. All three models were adjusted for age, sex, and verbal abilities, which have been shown to be associated with episodic memory ${ }^{1}$ (e.g., Herlitz, Nilsson, \& Bäckman, 1997; Herlitz \& Rehman, 2008; Salthouse, 2009).

We also examined the total effect of the independent variable on the dependent variable, required by the traditional methods of testing for mediation (Baron \& Kenny, 1986).

The total, direct, and indirect effects of control beliefs on memory performance were estimated by the MED3C SPSS macro (Hayes, Preacher, \& Myers, 2011), which generates percentile-based bootstrap confidence intervals (CI). Confidence intervals that did not encompass zero were considered significant. The test of the indirect effect was done using the bootstrapping method (1,000 bootstrap samples). First, the association between control beliefs and word list recall was analyzed in a simple model (controlling for age, sex, and verbal abilities). Then, the same association was examined in Model 3, which adjusted for covariates and the two potential mediators, namely state anxiety and task interference.

\footnotetext{
${ }^{1}$ The results did not change when educational attainment, depression, and self-rated health were entered as covariates, so we did not include them in the final models.
} 
In order to test whether age moderated each of the three paths of the meditational chain, we then retested the three models including the following interaction terms: age $\mathrm{x}$ control beliefs in Model 1, age x state anxiety in Model 2, and age $\mathrm{x}$ cognitive interference in Model 3.

\section{Results}

Table 1 reports means, standard deviations, and intercorrelations of all variables. In line with previous findings, younger adults, women, those with higher levels of education attainment, those with higher levels of verbal abilities, and those with higher control beliefs had higher scores on word list recall task, $r(147)=-.34, p<.001 ; r(147)=.22, p<.01$; $r(147)=.17, p<.05 ; r(147)=.20, p<.05 ; r(147)=.24, p<$ .01 , respectively.

With respect to the mediation chain (Table 2), for the first model of the joint significance test, the results revealed a significant negative linear association between control beliefs and state anxiety $\left[\beta_{1}=-.33, t(144)=-4.32, p<.001\right]$. In Model 2, there was a significant relationship between state anxiety and task interference $\left[\beta_{2}=.26, t(143)=3.17, p=\right.$ .002] and a significant association between control and cognitive interference $\left[B_{5}=-.20 ; t(143)=-2.58 ; p=.011\right]$. In Model 3, memory performance was regressed on control beliefs, state anxiety, and task interference. The results revealed a significant relationship between the level of interference and memory $\left[B_{3}=-.19, t(142)=-2.35, p=\right.$ $.020]$. The association between anxiety and memory performance was not significant $\left[\beta_{6}=-.14, t(142)=-1.79, p=\right.$ .075]. In summary, the three paths of interest $\left(\beta_{1}, \beta_{2}\right.$, and $\left.\beta_{3}\right)$ were jointly significant.

The total effect of control beliefs on memory was significant in the model adjusting for age, sex, and verbal abilities $[\beta=.22 ; t(144)=3.05 ; p=.003]$, but was nonsignificant in Model 3 when the mediators were included [direct effect: $\beta_{4}=.12 ; t(142)=1.59 ; p=.115$ ].

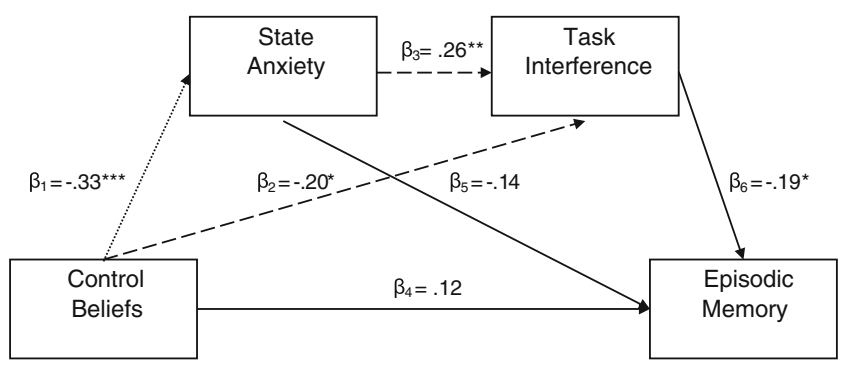

Fig. 1 Standardized regression coefficients corresponding to the threepath mediation model linking control beliefs to episodic memory. The dotted line represents the path tested in Model 1. Dashed lines represent the paths tested in Model 2. Solid lines represent the paths tested in Model 3. ${ }^{*} p<.05 ;{ }^{* *} p<.01 ; * * *<.001$
Also, the total indirect effect (i.e., control beliefs $\rightarrow$ state anxiety $\rightarrow$ task interference $\rightarrow$ episodic memory) was significant $\{95 \%$ CI $[.005, .498]\}$, providing evidence for full mediation.

The results also revealed that none of the three paths of the mediational chain was moderated by age. Age was included as a covariate, indicating that the models were robust, irrespective of age.

\section{Discussion}

The results provided empirical support for the theoretically driven three-path mediation model linking control beliefs with memory performance through state anxiety and task interference. Participants with lower control beliefs reported higher levels of state anxiety, which in turn increased the likelihood of distracting thoughts during the memory tasks. The failure to inhibit attention to distracting thoughts was detrimental to memory performance. This model held across age and while controlling for verbal abilities, education, and sex. There was no evidence that these relationships varied by age, suggesting the robust nature of the mechanisms linking individual differences in control beliefs with memory. On the basis of the present findings, low control beliefs can be considered a risk factor for poor functioning in both younger and older adults. Low control beliefs are indicative of a view that little can be done to influence outcomes or performance such as to maintain cognitive functioning and to prevent, slow, remediate, or compensate for memory changes in later life. Such a viewpoint has damaging motivational and behavioral consequences for memory functioning.

The associations between the variables involved in the three-path mediation model were assumed to be linear. However, we acknowledge that others have found nonlinear associations, especially for anxiety and cognitive performance (Bierman, Comijs, Rijmen, Jonker, \& Beekman, 2008), where a moderate level of anxiety may be adaptive. We analyzed a model in which we tested quadratic terms for control beliefs, anxiety, and task interference. Indeed, the quadratic term was significant for anxiety, in a model adjusted for age, sex, and verbal abilities, as well as in Model 3 (adjusted for age, sex, verbal abilities, control beliefs, and task interference). The quadratic plot revealed that the effects were largely linear, but with an asymptotic pattern, indicating that low and medium levels of anxiety were both similarly associated with better memory performance, in contrast with high anxiety levels. Thus, the quadratic results do not change the overall pattern of findings.

We acknowledge some limitations of the present study. Our measure of task interference was based on retrospective 
Table 2 Multiple regression models corresponding to the joint significance test of the three-path mediation

\begin{tabular}{|c|c|c|c|c|c|c|}
\hline \multirow[t]{2}{*}{ Predictors } & \multicolumn{2}{|c|}{ Model 1 (Outcome = State Anxiety) } & \multicolumn{2}{|c|}{ Model 2 (Outcome $=$ Task Interference) } & \multicolumn{2}{|c|}{ Model 3 (Outcome $=$ Episodic Memory) } \\
\hline & $\begin{array}{l}\text { Unstandardized (Standardized) } \\
\text { Parameter Estimate }\end{array}$ & SE & $\begin{array}{l}\text { Unstandardized (Standardized) } \\
\text { Parameter Estimate }\end{array}$ & $\mathrm{SE}$ & $\begin{array}{l}\text { Unstandardized (Standardized) } \\
\text { Parameter Estimate }\end{array}$ & SE \\
\hline Age & $-.001(-.04)$ & .002 & $-.01(-.29)^{* * *}$ & .002 & $-.14(-.46)^{* * *}$ & .022 \\
\hline Sex & $.10(.23)^{* *}$ & .034 & $-.01(-.01)$ & .034 & $1.05(.23)^{* *}$ & .333 \\
\hline Verbal abilities & $-.01(-.06)$ & .007 & $.002(.02)$ & .007 & $.25(.26)^{* *}$ & .071 \\
\hline Control beliefs & $-.31(-.33) * * *$ & .071 & $-.19(-.20)^{*}$ & .075 & $1.18(.12)$ & .742 \\
\hline Anxiety & & & $.26(.26)^{* *}$ & .082 & $-1.48(-.14)$ & .824 \\
\hline Task interference & & & & & $-1.90(-.19)^{*}$ & .810 \\
\hline
\end{tabular}

Model $1, R^{2}=.18, F(4,144)=8.11 ; p<.001 ;$ Model $2, R^{2}=.24, F(5,143)=9.12 ; p<.001 ;$ Model 3, $R^{2}=.33, F(6,142)=11.80 ; p<.001$. The values in bold correspond to the three paths of the mediational model

$* p<.05 * * p<.01 * * * p<.001$

reports. In future studies, it will be useful to include a concurrent, behavioral measure of task interference, as well as multiple indicators for our variables to disaggregate measurement reliability. It will also be of interest in future studies to employ an experimental design to explore the implications for memory when manipulating control, anxiety, or task interference. An experimental design will also be helpful for examining directionality and causality for the established associations.

Low perceived control may be considered a risk factor for poor functioning in later life, and the deleterious processes may begin early in midlife (Lachman \& Agrigoroaei, 2010), which raises the potential for intervention and prevention. Although the models were found to hold regardless of age, intervention programs may be most useful for older adults, for whom memory problems are more prevalent. The view that little can be done to prevent, slow, remediate, or compensate for memory changes in later life has important implications for daily living. For example, holding such a view could result in avoidance of memory-demanding situations, restriction of social engagements, anxiety about signs of memory loss (e.g., overgeneralization of memory failure to fear of Alzheimer's, fear of embarrassment at forgetting), failure to follow medical regimens (e.g., not using reminders or pill boxes), loss of independent living capacity because of reluctance to use organizational strategies, and failure to monitor medication schedule or remember appointments. These behaviors, in turn, can lead to greater dependence on others for instrumental activities of daily living.

Results of the present study can be useful for informing interventions to prevent, remediate, or minimize either the decrements in sense of control or the sequelae involving anxiety and rumination. For those interested in designing interventions on perceived control, there is encouraging evidence that control beliefs and related constructs such as memory self-efficacy are malleable (Hayslip, 1989; Lachman et al., 2011; McDougall, 2000; West, Bagwell, \& DarkFreudeman, 2008). For the suppression of intrusive thoughts and reduction of anxiety, previous experimental findings (Sarason \& Sarason, 1986; Sarason, Sarason, \& Pierce, 1995) are encouraging. Such interventions may involve comprehensive treatment approaches such as relaxation, biofeedback, cognitive restructuring, and/or strategy use training. For example, the results obtained by Hayslip (1989) provide support for the effectiveness of stress inoculation techniques to improve cognitive performance among older adults.

Past memory training programs such as the Advanced Cognitive Training for Independent and Vital Elderly (ACTIVE) have been successful in teaching strategies for solving cognitive test problems (Willis et al., 2006; Wolinsky et al., 2006), but more extensive treatment is needed to achieve optimal maintenance over time and generalizability across tasks and application to everyday functioning. In keeping with our conceptual framework, interventions should address memory-related beliefs to achieve lasting effects; otherwise, newly acquired techniques are not likely to be implemented (West et al., 2008). Beliefs about controllability of aging underlie much of the behavior and response to aging-related decline. Thus, we suggest that future studies plan to supplement traditional strategy training with enhancement of control beliefs, and reduction of fear and anxiety to achieve more sustained effects, especially for the most cognitively vulnerable populations - that is, older adults and those with low control beliefs. We demonstrated this approach in another domain involving control beliefs and anxiety. This multimodal intervention for fear of falling (A Matter of Balance) was successful in changing control beliefs and behavior and reducing fear, and is being used in hospital and community 
settings (Tennstedt et al., 1998). Findings from the present research on memory performance, one of the most prevalent concerns associated with aging, may be applied to developing similar interventions.

Author note The present research was supported by National Institute on Aging Grant RO1 AG 17920. We thank Angela Lee, Michael Polito, and Eileen Kranz Graham for their assistance with data collection.

\section{References}

Amrhein, P. C., Bond, J. K., \& Hamilton, D. A. (1999). Locus of control and the age difference in free recall from episodic memory. The Journal of General Psychology, 126, 149-164.

Andreoletti, C., Veratti, B. W., \& Lachman, M. E. (2006). Age differences in the relationship between anxiety and recall. Aging \& Mental Health, 10, 265-271.

Bandura, A. (1997). Self-efficacy: The exercise of control. New York: Freeman.

Baron, R. M., \& Kenny, D. A. (1986). The moderator-mediator variable distinction in social psychological research: Conceptual, strategic, and statistical considerations. Journal of Personality and Social Psychology, 51, 1173-1182.

Beaudreau, S. A., \& O'Hara, R. (2009). The association of anxiety and depressive symptoms with cognitive performance in communitydwelling older adults. Psychology and Aging, 24, 507-512.

Bierman, E. J. M., Comijs, H. C., Rijmen, F., Jonker, C., \& Beekman, A. T. F. (2008). Anxiety symptoms and cognitive performance in later life: Results from the longitudinal aging study Amsterdam. Aging \& Mental Health, 12, 517-523.

Brosschot, J. F., Gerin, W., \& Thayer, J. F. (2006). The perseverative cognition hypothesis: A review of worry, prolonged stress-related physiological activation, and health. Journal of Psychosomatic Research, 60, 113-124.

Brosschot, J. F., Godaert, G. L. R., Benschop, R. J., Olff, M., Ballieux, R. E., \& Heijnen, C. J. (1998). Experimental stress and immunological reactivity: A closer look at perceived uncontrollability. Psychosomatic Medicine, 60, 359-361.

Caplan, L. J., \& Schooler, C. (2003). The roles of fatalism, selfconfidence, and intellectual resources in the disablement process in older adults. Psychology and Aging, 18, 551-561.

Clapp, W. C., \& Gazzaley, A. (2010). Distinct mechanisms for the impact of distraction and interruption on working memory in aging. Neurobiology of Aging. Advance online publication, doi:10.1016/j.neurobiolaging. 2010.01.012

Coy, B., O'Brien, W. H., Tabaczynski, T., Northern, J., \& Carels, R. (2011). Associations between evaluation anxiety, cognitive interference and performance on working memory tasks. Applied Cognitive Psychology. Advance online publication, doi:10.1002/ acp. 1765

Czaja, S. J., Charness, N., Fisk, A. D., Hertzog, C., Nair, S. N., Rogers, W. A., \& Sharit, J. (2006). Factors predicting the use of technology: Findings from the Center for Research and Education and Aging and Technology Enhancement (CREATE). Psychology and Aging, 21, 333-352.

Derakshan, N., \& Eysenck, M. W. (2009). Anxiety, processing efficiency, and cognitive performance: New developments from attentional control theory. European Psychologist, 14, $168-176$

Dobson, P. (2000). An investigation into the relationship between neuroticism, extraversion and cognitive test performance in selection. International Journal of Selection and Assessment, 8, 99-109.

Ekstrom, R. B., French, J. W., Harman, H. H., \& Derman, D. (1976). Manual for kit of factor-referenced cognitive tests. Princeton, NJ: Educational Testing Service.

Endler, N. S., Speer, R. L., Johnson, J. M., \& Flett, G. L. (2001). General self-efficacy and control in relation to anxiety and cognitive performance. Current Psychology: Developmental, Learning, Personality, Social, 20, 36-52.

Eysenck, M. W., \& Calvo, M. G. (1992). Anxiety and performance: The processing efficiency theory. Cognition and Emotion, 6, 409-434.

Eysenck, M. W., Derakshan, N., Santos, R., \& Calvo, M. G. (2007). Anxiety and cognitive performance: Attentional control theory. Emotion, 7, 336-353.

Ferraro, F. R., \& Washington, T. L. J. (2005). Impact of test anxiety and self-efficacy on test performance. Psychology and Education: An Interdisciplinary Journal, 42, 8-16.

Hammermaster, C. S. (1989). Levels of performance and cognitive interference in test-anxious subjects. Alberta Journal of Educational Research, 35, 164-170.

Hasher, L., \& Zacks, R. (1988). Working memory, comprehension, and aging: A review and a new view. In G. H. Bower (Ed.), The psychology of learning and motivation: Advances in research and theory (Vol. 22, pp. 193-225). San Diego, CA: Academic Press.

Hayes, A. F., Preacher, K. J., \& Myers, T. A. (2011). Mediation and the estimation of indirect effects in political communication research. In E. P. Bucy \& R. L. Holbert (Eds.), Sourcebook for political communication research: Methods, measures and analytical techniques (pp. 434-465). New York, NY: Routledge.

Hayslip, B. (1989). Alternative mechanisms for improvements in fluid ability performance among older adults. Psychology and Aging, 4, 122-124.

Herlitz, A., Nilsson, L.-G., \& Bäckman, L. (1997). Gender differences in episodic memory. Memory \& Cognition, 25, 801-811.

Herlitz, A., \& Rehman, J. (2008). Sex differences in episodic memory. Current Directions in Psychological Science, 17, 52-56.

Hertzog, C., Dixon, R. A., \& Hultsch, D. F. (1990). Relationships between metamemory, memory predictions, and memory task performance in adults. Psychology and Aging, 5, 215-227.

Hertzog, C., Kramer, A. F., Wilson, R. S., \& Lindenberger, U. (2008). Enrichment effects on adult cognitive development: Can the functional capacity of older adults be preserved and enhanced? Psychological Science in the Public Interest, 9, 165.

Hertzog, C., McGuire, C. L., \& Lineweaver, T. T. (1998). Aging, attributions, perceived control, and strategy use in a free recall task. Aging, Neuropsychology, and Cognition, 5, 85-106.

Hogan, M. J. (2003). Divided attention in older but not younger adults is impaired by anxiety. Experimental Aging Research, 29, 111136.

Jopp, D., \& Hertzog, C. (2007). Activities, self-referent memory beliefs, and cognitive performance: Evidence for direct and mediated relations. Psychology and Aging, 22, 811-825.

Kemeny, M. E. (2003). The psychobiology of stress. Current Directions in Psychological Science, 12, 124-129.

Kirschbaum, C., Prüssner, J. C., Stone, A. A., Federenko, I., Gaab, J., Lintz, D., ..., Hellhammer, D. H. (1995). Persistent high cortisol responses to repeated psychological stress in a subpopulation of healthy men. Psychosomatic Medicine, 57, 468-474.

Klein, K., \& Boals, A. (2001). The relationship of life events stress and working memory capacity. Applied Cognitive Psychology, $15,565-579$.

Krause, N. (2007). Age and decline in role-specific feelings of control. Journal of Gerontology: Social Sciences, 62B, S28-S35. 
Kurosowa, K., \& Harackiewicz, J. M. (1995). Test anxiety, selfawareness, and cognitive interference: A process analysis. Journal of Personality, 63, 931-951.

Lachman, M. E., \& Agrigoroaei, S. (2010). Promoting functional health in midlife and old age: Long-term protective effects of control beliefs, social support, and physical exercise. PloS One, 5, e13297.

Lachman, M. E., Agrigoroaei, S., Murphy, C., \& Tun, P. (2010). Frequent cognitive activity compensates for education differences in episodic memory. The American Journal of Geriatric Psychiatry, 18, 4-10.

Lachman, M. E., \& Andreoletti, C. (2006). Strategy use mediates the relationship between control beliefs and memory performance for middle-aged and older adults. Journal of Gerontology: Psychological Sciences, 61B, P88-P94.

Lachman, M. E., Andreoletti, C., \& Pearman, A. (2006). Memory control beliefs: How are they related to age, strategy use and memory improvement? Social Cognition, 24, 359-385.

Lachman, M. E., Baltes, P. B., Nesselroade, J. R., \& Willis, S. L. (1982). Examination of personality-ability relationships in the elderly: The role of the contextual (interface) assessment mode. Journal of Research in Personality, 16, 485-501.

Lachman, M. E., Neupert, S. D., \& Agrigoroaei, S. (2011). The relevance of control beliefs for health and aging. In K. W. Schaie \& S. L. Willis (Eds.), Handbook of the psychology of aging (7th ed., pp. 175-190). San Diego, CA: Academic Press.

Lupien, S. J., Fiocco, A., Wan, N., Maheu, F., Lord, C., Schramek, T., \& Tu, M. T. (2005). Stress hormones and human memory function across the lifespan. Psychoneuroendocrinology, 30, 225-242.

Lupien, S. J., Gaudreau, S., Tchiteya, B. M., Maheu, F., Sharma, S., Nair, N. P. V., ..., Meaney, M. J. (1997). Stress-induced declarative memory impairment in healthy elderly subjects: Relationship to cortisol reactivity. Journal of Clinical Endocrinology and Metabolism, 82, 2070-2075.

MacKinnon, D. P., Lockwood, C. M., Hoffman, J. M., West, S. G., \& Sheets, V. (2002). A comparison of methods to test mediation and other intervening variable effects. Psychological Methods, 7, 83104.

May, C. P., Hasher, L., \& Kane, M. J. (1999). The role of interference in memory span. Memory \& Cognition, 27, 759-767.

Mayer, D. M., \& Hanges, P. J. (2003). Understanding the stereotype threat effect with "culture-free" tests: An examination of its mediators and measurement. Human Performance, 16, 207-230

McDougall, G. J. (2000). Memory improvement in assisted living elders. Issues in Mental Health Nursing, 21, 217-233.

Miller, L. M. S., \& Lachman, M. E. (1999). The sense of control and cognitive aging: Toward a model of mediational processes. In $\mathrm{T}$. M. Hess \& F. Blanchard-Fields (Eds.), Social cognition and aging (pp. 17-41). New York, NY: Academic Press.

Neupert, S. D., Stawski, R. S., \& Almeida, D. M. (2008). Considerations for sampling time in research on aging: Examples from research on stress and cognition. In S. M. Hofer \& D. F. Alwin (Eds.), Handbook of cognitive aging: Interdisciplinary perspectives (pp. 492-505). Los Angeles, CA: Sage Publications.

Peterson, C., Maier, S., \& Seligman, M. E. P. (1993). Learned helplessness: A theory for the age of personal control. New York, NY: Oxford University Press.

Riggs, K. M., Lachman, M. E., \& Wingfield, A. (1997). Taking charge of remembering: Locus of control and older adults' memory for speech. Experimental Aging Research, 23, 237-256.

Rowe, J. W., \& Kahn, R. L. (1998). Successful aging. New York, NY: Pantheon Books.
Salthouse, T. A. (2009). When does age-related cognitive decline begin? Neurobiology of Aging, 30, 507-514.

Sarason, I. G. (1988). Anxiety, self-preoccupation and attention. Anxiety Research, 1, 37.

Sarason, I. G., \& Sarason, B. R. (1986). Experimentally Provided Social Support. Journal of Personality and Social Psychology, $50,1222-1225$

Sarason, I. G., Sarason, B. R., Keefe, D. E., Hayes, B. E., \& Shearin, E. N. (1986). Cognitive interference: Situational determinants and traitlike characteristics. Journal of Personality and Social Psychology, 51, 215-226.

Sarason, I. G., Sarason, B. R., \& Pierce, G. R. (1995). Cognitive interference at the intelligence-personality crossroads. In D. H. Saklofske \& M. Zeidner (Eds.), International handbook of personality and intelligence (pp. 285-296). New York, NY: Plenum Press.

Seeman, T. E., McAvay, G., Merrill, S., Albert, M., \& Rodin, J. (1996). Self-efficacy beliefs and change in cognitive performance: MacArthur studies of successful aging. Psychology and Aging, $11,538-551$

Seeman, T. E., \& Robbins, R. J. (1994). Aging and hypothalamicpituitary-adrenal response to challenge in humans. Endocrine Reviews, 15, 233-260.

Sheikh, J. I., \& Yesavage, J. A. (1986). Geriatric Depression Scale: Recent evidence and development of a shorter version. In T. L. Brink (Ed.), Clinical gerontology: A guide to assessment and intervention (pp. 165-173). New York, NY: Haworth Press, Inc.

Sinoff, G., \& Werner, P. (2003). Anxiety disorder and accompanying subjective memory loss in the elderly as a predictor of future cognitive decline. International Journal of Geriatric Psychiatry, 18, 951-959.

Smallwood, J., McSpadden, M., \& Schooler, J. M. (2008). When attention matters: The curious incident of the wandering mind. Memory \& Cognition, 36, 1144-1150.

Spielberger, C., Gorsuch, R., \& Luskene, R. (1970). STAI manual for the state-trait anxiety inventory. Palo Alto, CA: Consulting Psychologists Press.

Stawski, R. S., Sliwinski, M. J., \& Smyth, J. M. (2006). Stress-related cognitive interference predicts cognitive function in old age. Psychology and Aging, 21, 535-544.

Stawski, R. S., Sliwinski, M. J., \& Smyth, J. M. (2009). The effects of an acute psychosocial stressor on episodic memory. European Journal of Cognitive Psychology, 21, 897-918.

Taylor, A. B., MacKinnon, D. P., \& Tein, J.-Y. (2008). Tests of the three-path mediated effect. Organizational Research Methods, 11, 241-269.

Tennstedt, S., Howland, J., Lachman, M. E., Peterson, E. W., Kasten, L., \& Jette, A. (1998). A randomized, controlled trial of a group intervention to reduce fear of falling and associated activity restriction in older adults. Journal of Gerontology: Psychological Sciences, 53B, P384-P392.

Tun, P. A., \& Lachman, M. E. (2010). The association between computer use and cognition across adulthood: Use it so you won't lose it? Psychology and Aging, 25, 560-568.

Valentijn, S. A. M., Hill, R. D., Van Hooren, S. A. H., Bosma, H., Van Boxtel, M. P. J., Jolles, J., \& Ponds, R. W. H. M. (2006). Memory self-efficacy predicts memory performance: Results from a 6-year follow-up study. Psychology and Aging, 21, 165-172.

van Hooren, S. A. H., Valentijn, S. A. M., Bosma, H., Ponds, R. W. H. M., van Boxtel, M. P. J., \& Jolles, J. (2005). Relationship between health status and cognitive functioning: A 6-year followup of the Maastricht Aging Study. Journal of Gerontology: Psychological Sciences, 60B, P57-P60.

West, R. L., Bagwell, D. K., \& Dark-Freudeman, A. (2008). Selfefficacy and memory aging: The impact of a memory intervention based on self-efficacy. Aging, Neuropsychology, and Cognition, 15, 302-329. 
West, R. L., \& Yassuda, M. S. (2004). Aging and memory control beliefs: Performance in relation to goal setting and memory selfevaluation. Journal of Gerontology: Psychological Sciences, 59B, P56-P65.

Wetherell, J. L., Reynolds, C. A., Gatz, M., \& Pedersen, N. L. (2002). Anxiety, cognitive performance, and cognitive decline in normal aging. Journal of Gerontology: Psychological Sciences, 57B, P246-P255.

Willis, S. L., Tennstedt, S. L., Marsiske, M., Ball, K., Elias, J., Koepke, K. M., ..., Wright, E. (2006). Long-term effects of cognitive training on everyday functional outcomes in older adults. Journal of the American Medical Association, 296, 2805-2814.
Windsor, T. D., \& Anstey, K. J. (2008). A longitudinal investigation of perceived control and cognitive performance in young, midlife and older adults. Aging, Neuropsychology, and Cognition, 15, 744-763.

Wolinsky, F. D., Unverzagt, F. W., Smith, D. M., Jones, R., Wright, E., $\&$ Tennstedt, S. L. (2006). The effects of the ACTIVE cognitive training trial on clinically relevant declines in health-related quality of life. Journal of Gerontology: Social Sciences, 61B, S281-S287.

Yee, P. L., Edmondson, B., Santoro, K. E., Begg, A. E., \& Hunter, C. D. (1996). Cognitive effects of life stress and learned helplessness. Anxiety, Stress, and Coping, 9, 301-319. 